\title{
A Cluster Approach towards Enhancing Chinese- American
}

\author{
Trade Opportunities
}

\author{
William J. Lawrence and Weidong Sun \\ New York Institute of Technology, USA \\ Jiangsu Finance and Economics College of Vocational Technology, China \\ E-mail:wlawrence@pipeline.com
}

Fund Project: Jiangsu Government-sponsored Scholarship Project for visiting scholars. (Su foreign education [2008]45th, and the 2009 Research Project from Jiangsu Provincial Department of education.

\begin{abstract}
For some time now, China has relied heavily on industrial clusters to create an international competitive edge. While the program has been largely successful, China has increasingly had to cope with severe accusations from its trading partners who claim a policy of dumping and selling low quality products with flaws, and hazardous outcomes. Claims are also made that China has not been as mindful of its resource utilization, environment impact, and overall economic efficiency as it should be. The thrust of this paper recognizes that opportunities exist for both the US and China to use this period as one of enhanced communication and cooperative ventures and planning initiatives. It is a hypothesis that cluster analysis offers a major vehicle that shows how all nations can begin to meet the needs of their people and do it in an environmentally and economically responsible manner.
\end{abstract}

Keywords: Industrial cluster, Smooth trade, The US-China

\section{Introduction}

Michael E. Porter, an internationally recognized scholar on competitive strategy, is the Bishop William Lawrence University Professor, based at Harvard Business School. He created the Cluster concept as a tool to better define industrial and geographic concentration both within and among nations. Professor Porter first introduced the concept of Clusters in 1990, which has gained wide acceptance throughout the world. Examples of its implementation as a public-private initiative currently exist in almost every country. Industrial clusters represent geographic concentration of interconnected enterprises in a particular industry that share related production inputs, specialized labor pools, distribution and communication channels, and network association. Clusters can be characterized as being integrated networks of production within strongly interdependent firms, including specialized supplier and extending to knowledge support agents such as universities, research institutes, and engineering companies. Clusters can also exist among bridge institutions such as brokers, and consultants as well as distribution channels and customers themselves, all of which are linked to each other in a value-adding production chain. The cluster approach focuses on the linkages and interdependence between actors in the overall network of producing products and services, contributing to the creation of innovation and a more efficient utilization of scarce resources. Porter's work on clustering was given a trade and global boost in a 1991 (Note 2) study by Paul Krugman who was able to show how the concept was also of importance to government trade planners and policy makers. While the original objective of clusters centered on how national state or regional economic development planners could increase the competitive environment, as globalization became an inherent part of the production and design process, more trade and international opportunities evolved.

Porter used various linkages to define a cluster. They could be purely industrial where different interdependent sectors link to each other such as within the various stages of processing of a natural resource or that of subsequent stages of fabrication. The linkage could also be geographically defined in order to keep distribution, transportation and inventory costs down, or in the case of a global cluster, where specialization or production costs and processes are more economically shared. A cluster could conceivably even be created within competing industrial sectors where for certain projects it would be economically efficient to cluster thereby creating a competitive advantage over other potential bidders.

Mills, Reynolds and Reamer (2008) (Note 3) recognized the importance of cluster analysis in a Brookings study and 
called for the federal government to fund the development of a national cluster registry and data base so that industries and planners could better take advantage of the productivity and enhanced resource allocation opportunities offered by clustering.

Cluster analysis has not been without its critics, Barkley and Henry (2001) (Note 4) focused on regional economies and concluded that while the overall approach to clustering had several advantages, the authors considered it critical that each case be reviewed very carefully to avoid the formation of joint ventures that might not be able to survive competitive and growth conditions in their respective industries. Martin and Sunley (2003) (Note 5) were also concerned that there did not exist a formal theory for clustering that in their opinion made it very difficult for researchers to analyze the ultimate benefits and costs in this approach to economic development strategies.

As various nations and planners begin to further explore the opportunities clustering offers as an economic development and trade tool there will surely be more data made available for analysis and review of the concept. Clearly, the fact that so many national and international organizations have embraced the concept makes it incumbent on the part of researchers and policy makers to continue to seek even more ways that clusters as an industrial development tool can better foster economic efficiency and better trade relations and opportunities.

\section{An Overview of Industrial Clusters in China}

China has created a fairly sophisticated system of industrial clusters in many areas centered principally on their natural market share within domestic as well as global markets. This policy is most evident in the eastern and southern coastline regions, for example, Zhejiang province, which is in the southeast of China. Zhejiang Province has more than 500 villages and towns, many of which have formed their own unique cluster. The total output of these villages and towns accounts for roughly half of the province's industry product. The cluster phenomena consisting of a variety of industries has been created in Guangdong province as well. It has an estimated 60 towns out of all 240 towns in Guangdong that have formed a rather large scale of clusters primarily within traditional industry fields. Moreover, the southern areas of Jiangsu province have formed several IT industry clusters, Jingin county(in Fujian province) has formed shoe industry clusters, Shouguang county(in Shandong province) has formed a vegetable industry cluster, Qinhou county(in Hebei province) has formed a wool industry cluster and Zhongguan village(in Beijing) has also formed an IT industry cluster.

From table 1, we can see how these industrial clusters play an important role in China.

$<$ Insert Table 1 here $>$

However, with time many management problems in the industrial clusters began to emerge, often resulting from the low management skills of entrepreneurs, out date of technology or increasing labor cost. In addition, a growing low commitment of working hard, effective mutual cooperation, to mention only a few, began to further exacerbate the problems. Perhaps this phenomenon can be categorized as management deficiencies suffering from excessive growth. It is however, time for clustered firms to upgrade their management level and for the clustering process to move from the low industrial levels to the relatively higher one.

\section{Reasons behind the Growth of a Cluster Approach towards Industrial Development and Trade}

Professor David L. Barkley and Professor Mark S. Henry in a 2001 paper (Note 6) concluded that there were basically four important advantages underlying industrial clusters including: a) strengthening localization economies, b) facilitating industrial reorganization, c) encouraging networking among enterprises and d) permitting greater focusing of public resources. Their analysis shows the benefits from the cluster from the angle of the macroeconomic perspective.

There exists one other intrinsic strength that provides and incentive for an individual enterprise to join an industrial cluster. We have chosen to use a hypothesized case to make our point.

Assume that there are two separate and distinct retail merchants who are each selling cool drinking water along a linear beach. Let us further assume that; a) the merchandise they sell is of the same quality and sold at the same price; b) consumers are scattered evenly along the beach; c) customers are time and convenient oriented and always prefer to buy cool drinking water from a nearby stall; and d) Our two merchants have an exclusive agreement prohibiting any other competitors entering this market. In order to describe our model conveniently, we define that the beach length is 1 , the left point being 0 and the right point being 1 . According to geographic optimization, merchant one would locate his stall at $1 / 4$ and merchant 2 would locate at $3 / 4$ because doing so would minimize overall consumer convenience giving each merchant equal access to their respective market share. Although such an arrangement seems fair and reasonable, the reality itself is nevertheless not so simple. Both merchants do the same business, creating an unavoidable competition between them. Absent an agreement to the contrary, each merchant would have an incentive to relocate his stall a little further down the beach towards the territory of the other's. He would do so in hopes of winning some consumers from the other. The other merchant might also consider taking a similar action towards the competitor's territory. Therefore, the interesting competitive forces provided a natural incentive such that both merchants will gradually move their stalls toward each other until they each arrive at the middle point of the beach. A clustering agreement however, would have 
both merchants agree to an overall location pattern, better designed to serves the customers and their time.

\section{The Impact of China's Industrial Cluster Policies on US/China Trade}

Commencing with China's 2001 accession into the WTO the growth in China's exports has increased annually, going from $20.1 \%$ in 2001 to $40 \%$ of its economy in 2008 . The trend strongly reflects the overall dependence of China's economy on its export trade which further ties Chinese growth to that of its trading partners. Besides, the high export volume also tends to cause main trading partners' trade deficit. At present, trade imbalance between US and China is a top concern in US-China relation. Statistics provided by the American Chamber of Commerce indicates that between 2001 and 2008, the US trade deficit with China increased from $\$ 83.10$ to $\$ 268.04$ billion (excluding service trade, see table 2), accounting for 28.8 of the US total trade deficit. Asking China to take measures to increase inputs from America and decrease trade surplus to the US has become a strong argument from American authorities. Strong concerns continue to exist on the part of all trading nations that China's increasing demand of oil and other energy resources may cause harm to the international economic order. Furthermore, the US worries that China's huge exports may further erode US job losses, a growing concern throughout American labor markets. It has been estimated that approximately $70 \%-80 \%$ of China's exports come from China's current industrial clusters. (Note 7) Therefore, if we want to solve China's foreign trade problems and overall balance of trade, we must pay close attention to industrial clusters and find ways to better distribute this output within China's borders as well as with its trading partners.

$<$ Insert Table 2 here $>$

\section{Industrial Clusters and the Balance of Trade Issue}

\subsection{The trade issue}

Major criticism of China's trade and economic development strategy has come primarily from its major trading partner, the United States. The US has also criticized China for dumping, and selling merchandise of low quality and in some cases with serious production and or design flaws.

Criticism has also pointed towards China's concentration on economic growth at the expense of a more rational utilization of its resources, further damaging the environment, and not being as mindful of economic efficiency as Chinese planners and manufactures might have been. The World Bank cited 16 Chinese cities out of 20 as the worlds most polluted.

In a recent study of carbon dioxide emissions, the most damaging of all greenhouse gases, a Dutch institute (Netherlands Environmental Agency, 2007) concluded that China has surpassed the US and is now the largest CO2 emitter in the world. This listing was based on the overviews on energy use as compiled by British Petroleum. (Note 8) Anything China can do to reduce its footprint in this area would be most welcomed as a member of the world community, Clusters, well thought out and implemented with an objective towards technological and environmental efficiencies offer one opportunity to do just this.

\subsection{Probable solutions}

(1) Among the WTO member states, the US has the second largest number of anti-dumping cases against China which has led to much confusion and debate within Chinese business leaders. China recognizes that America is implementing increased protectionism. But President Obama said, "We can't go back to the era where the Chinese or the Germans or other countries just are selling everything to us, but we're not selling anything to them". Just on Sep.11, 2009, President Obama announced that he would impose a 35 percent tariff on automobile and light-truck tires imported from China. Meanwhile, China, not unexpectedly, also took some countermeasures in reaction to this dispute. To some extent, the root reason for the dispute lies in the different cost and quality standards of merchandise that both sides hold. According to the WTO rules, as long as a country is not recognizes as a market economy country, any WTO member can measure the dumping extent of its enterprises by utilizing a third country's (substitute country) prices, not its domestic prices or costs. Therefore, since China is not recognized as market economy country by the US, the domestic prices of China's products will not be recognized as well, hence, the US has usually taken comparable prices of a third country to measure the dumping extent of Chinese enterprises, but China argues that this measure is unfair because the third country's cost may higher than that in China. So, in order to know Chinese merchandise' cost structure and solve the anti-dumping dispute permanently, the US and China need to find a better way to negotiate a more reasonable and workable comparative strategy towards evaluating these exchanges. However, the most important and also the first step, we think, is to implement a stronger and more workable system to communicate and cooperate. Only when both countries trust each other and consider the problems as faced by our trading partners can trade issues be solved easily.

(2) Chinese production has historically been associated with the output of relatively inexpensive goods that traditionally relied on an abundant and low cost labor supply to meet the demands of the market. As Chinese industrial policies developed, and became more capital intensive a significantly higher level of productivity was realized. China rapidly became more diversified in terms of its productive capacity and output choices. The conscious movement towards cluster production has made a more diversified production mix possible as well as a natural outgrowth of modernization. 
These changes in Chinese production capacity occurred as the visible shift towards a more service based economy became a reality throughout the American economy. This emerging dynamic has created a more diversified demand for imported goods on the part of the American consumer, products which are now almost exclusively produced outside of domestic American production facilities. Chinese products have been warmly received by the American consumer. However, the America market has also become more diversified with some consumers seeking high quality merchandise while others continue to seek low-priced merchandise. This change has provided a great opportunity for China as well as the need for its producers to prepare a wider range of products to meet this new demand for imports on the part of the United States. One result of this change is that the more diversified demand for any given product must now recognize the need for different levels of quality reflecting different pricing levels as well, creating a wider choice for the American consumer who will then be able to select their desired merchandise at the price and quality levels most desired.

It might at first appear that this diversification will break down the economies of scale enjoyed by the cluster approach to production as currently implemented and indeed even being expanded. This does not however, need to be the case, Upgrading and diversifying the industrial cluster's production level will place upon the manufacturer a great need for more efficient inputs, as well as intensified research and development, to improve techniques as well as technology, the implementation of stricter management measures and improve the competence of employees, all of which open great opportunities for cluster collaboration between American and Chinese management. In the past, China managed to overcome these limitations mainly by absorbing foreign capital or through the creation of temporary joint ventures. The current global financial crisis has significantly reduced opportunities for this strategy to continue, indeed, it is now recognized that capital funds can only solve some these contemporary production problems. A conscious effort at enhancing a targeted industrial cluster's core competence is most important, and can best be accomplished by taking advantage of American advanced knowledge and by attracting American talents to China to augment Chinese production, engineering, and product design. China has the labor costs advantage, while America has technology and capital advantage. A comprehensive mutually beneficial merging of both advantages is certain to transform and enhance the Chinese industrial cluster. A more aggressive merger of American and Chinese manufacturing and administration skills is also an aid to propel the transition towards smoother overall trade relations. This strategy is directly in line with Porter's concept of geographic clusters, all designed to enhance productivity and minimize resource utilization. According to five sets of actors composing cluster (see chart 1), Chinese clusters can combine with American companies, research communities and financial institutions to group a global cluster or upgrade the primitive one.

$<$ Insert Chart 1 here $>$

(3) Any new ideas involving economic development or production must now take its environmental footprint directly into consideration. All nations must accept the fact that we live on a finite planet with finite resources.

For the past 15 years China has witnessed a rapid rate of growth that has moved it into third place among our world's economies. As the world gets ever smaller in terms of the intellectual and time components of exchange, China needs to better focus on conservation of world resources such that the most efficient production processes flow from a global standard and not only a national one. At the same time, America needs to become a more active and willing partner to Chinese economic reform options. As one of the world's most rapidly developing nations, China is facing significant economic, social, and political challenges as it comes to terms with its next phase of economic expansion. In order to create a sustainable and stable growth strategy, China must reform and innovate more deliberately. China needs American technology management expertise, and administration skills to recreate the next phase of Chinese industrial clusters, and America needs China to lend its huge industrial capacity to become a more receptive and effective trading as well as producing partner. Commemorate with the creation of a more efficient economic growth strategy China must also think of ways to increase its domestic markets, a cornerstone to any stable and sustainable economy. As long as the US and China cooperate closely, business relations, political and social differences, and expanded trade that benefits all parties easily become achievable goals.

(4) China may not confine itself to the traditional industrial clusters. China can learn from America and take the advantage of America's advanced technology and administration skills so that it can more smoothly enter new industrial clusters that stand for new economy, such as tourism, music, sports, arts, film, dance, hotel, finance, insurance, education. Traditional industrial clusters' products are tangible and must incur raw materials costs. While these new industries' products are intangible they contain considerably less cost in solid raw materials they also are generally low level polluters as well. Service sector production is typically considerably less polluting than that of most manufacturing production, especially. Service output is a rapidly growing component of the nominal Gross domestic product of both China and America During recent decades, the importance of services to the global economy has steadily grown while the importance of goods has somewhat declined. It is a general rule that as the national economy develops, the service sector percentage of GDP becomes higher. With the notable exception of China, all the major economies, such as the European Union, the U.S, Japan and Germany, have more than $70 \%$ or their GDP from their respective service sectors. China's services are only $40 \%$, of its GDP, which is lower than the world average level of $64 \%$. From the fact we can explain why pollution in 
China continues to be a problem. Of course, this also indicates that China has a vast potential in service industry. If China wants to attain a positive impact in tackling its pollution problems, it must not only upgrade the existing traditional industrial clusters as a percentage in GDP, as well as enhance its service sector output.

Moreover, it is totally practical for China to transform it industrial clusters. Pittsburgh has set a good example. Pittsburgh has transformed itself from one of America's dirtiest cities into what is now a beautiful and clean city because of its successful transition from traditional industrial clusters to modern ones. Today, Pittsburgh has not only a viable, successful, and healthy steel cluster, but also a growing and healthy tourism and IT clusters. The economic environment has changed markedly during recent years, with most of the changes being driven by the revolution in information and communication technologies and by the emergence of a knowledge-based economy.

China has successfully taken advantage of foreign capital and skills to achieve ideal effects on the goods industries. It is now a good time to turn its attention towards a higher concentration on its service industries as well, merging with American experience, technology, skills and capitals in all sectors. American service industries are among the most developed in the world and many opportunities for joint development exist for China to take advantage of.

In fact, China and the U.S have both managed to create some successful examples of service industries cooperation. Motorola, Intel, IBM, Cisco, and many other American IT Firms companies have all crowded into China industrial clusters and collaborated with Chinese firms.

Besides, there are many other service cooperation cases. KFC has opened 2600 restaurants in China. Macdonald has opened more than 1200 outlets in China. Although Macdonald's scale is not as big as KFC's, it has always abided by an efficient strategy that each of its restaurants are always geographically close to KFC, which encourages more fast food industries to concentrate in the cluster.

It is a general rule that as the national economy develops, the service sector percentage of GDP becomes higher. With the notable exception of China, all the major economies, such as the European Union, the U.S, Japan and Germany, have more than $70 \%$ or their GDP from their respective service sectors. China's services are only $40 \%$, of its GDP(see table 3 ), which is lower than the world average level of $64 \%$. Of course, this also indicates that China has a vast potential in service industry. From those cooperative efforts in the past and intended cooperation in the future, we can see that China is an emerging new market in service industries cluster with much potentials and combination of both China and the U.S can surely achieve a better operation results.

$<$ Insert Table 3 here $>$

\section{Conclusions}

The US and China are the worlds second largest trading partners, which means that there is great potential in the US-China economy for expanded global cooperation. America's huge financial and trade deficits requires it try to find a way to attract external funds and markets, while China's large surpluses and domestic requirements create opportunities to upgrade its traditional industrial clusters and expand its service industrial clusters by absorbing international talents. The US and China have many complementary goals and opportunities. As long as they cooperate well and exert their respective strengths, and recognize their individual weaknesses, they are both sure to create the greater global clustered markets. Opportunities exist in the silk and fabric, agriculture, wool, electronics automobile, steel, or even aircraft production sectors that can be both expanded and explored. The US still has a technological advantage, and China has labor and natural resources advantage. The combination of the two advantages should be definitely a resource of innovation and smoother trade relations that will lead to an even greater level of social, political and economic benefits for both countries.

\section{References}

Barkley, David L., \& Mark S. Henry. (2001). Advantages and disadvantages of targeting industry clusters, Clemson University Public Service Activities. Regional Economic Development Research Laboratory Report, 09-2002-01.

Bishop, Bernard. (2007). Why did China Benefit from a Joint Venture Policy? A Case Study of Shanghai. China \&World Economy, 89 - 103, Vol. 15, No. 2.

Duan Yujing., \& Shi Donglian. (2007). Study on the clustering of a typical industry: a case of apple industry in Shaanxi Province, China. Ecological Economy, 312-321, 3 March.

JIAN, Xinhua \& ZHANG, Hao. (2008). Urgency Required in Changing the Growth Mode of China's Foreign Trade. China Economist, 126-130, 8 May.

Karen G. Mills., Elisabeth B. Reynolds., \& Andrew Reamer. Clusters and Competitiveness: A New Federal Role for Stimulating Regional Economies. Metropolitan Policy Program at Brookings, April 2008.

Kumakura, Masanga. (2007). What's So Special about China's Exports? A Comment. China \& World Economy, 18 - 37 , Vol. 15, No. 5 . 
Martin, Ron., \& Sunley Peter. (2003). Deconstructing Clusters: Chaotic Concept or Policy Panacea, Journal of Economic Geography, 3.

Michael E. Porter. (1990). The Competitive Advantage of Nation. Macmillan Press.

Paul Krugman. (1991). Geography and Trade Cambridge MA. London, MIT Press.

Peng, Wensheng., Chang Shu., \& Raymond Yip. (2007). Renminbi Derivatives: Recent Development and Issues. China \&World Economy, 1 - 17, Vol. 15, No. 5.

State of Connecticut; Department of Economic and Community Development, Connecticut Industry Clusters. (2009). Progress Report.

Steinbock, Dan. (2008). US Presidential Election 2008: Policy implications for US-China Trade and Investment. China and World Economy, 40-56, vol.16, No.3.

Yang Jialong. (2003). Analysis of the Current Industrial Growth Pattern. China \&World Economy, 44 - 48, Vol. 11, No. 5.

Yuefen, Li. (2007). Why China Has Become a Target of Anti-dumping Activities? China Economist, 48-52, 8 Jan.

\section{Notes}

Note 1. Michael E. Porter, The Competitive Advantage of Nation, Macmillan Press, 1990.

Note 2. Paul Krugman, Geography and Trade Cambridge MA, London, MIT Press, 1991.

Note 3. Karen G. Mills, Elisabeth B. Reynolds, Andrew Reamer; Clusters and Competitiveness: A New Federal Role for Stimulating Regional Economies. Metropolitan Policy Program at Brookings, April 2008.

Note 4. Barkley, David L. Mark S. Henry, 2001, “Advantages and disadvantages of targeting industry clusters, Clemson University Public Service Activities " Regional Economic Development Research Laboratory Report 09-2002-01.

Note 5. Martin, Ron and Sunley Peter; Deconstructing Clusters: Chaotic Concept or Policy Panacea, Journal of Economic Geography, 3, 2003.

Note 6. The same as 4

Note 7. China Market Research Center, 2008-2009 China Customs data Analysis on China Clusters' Export and Import, 2009.

Note 8. http://seattletimes.nwsource.com/html/nationworld/2003756624_wdig21.html

Table 1. Some examples of China clusters

\begin{tabular}{|l|l|}
\hline Location/Product Name & Market Share(\%)(Domestic or Global) \\
\hline Wenzhou/Cigarette Lighter & 80 (Global) \\
Hangii/Tooth Brush & 80 (Domestic), 22( Global) \\
Fushan/Pottery & 80 (Domestic), 30(Global) \\
Yongjia/Cloth Button & 80 (Domestic) \\
Chenzhou/Tie & 90 (Domestic) \\
Yiwu/Little Merchandise & 70 (Domestic) \\
Zhuji/Sock & 65(Domestic) \\
Shaoxing/Texile & 33 (Domestic) \\
Wenzhou/Shoes & 26 (Domestic) \\
Hainin/Leather & 25 (Domestic) \\
\hline$\ldots$ & $\ldots$ \\
\hline
\end{tabular}

Note: Every location above is a city belonging to a province in China. 
Table 2. The U.S Trade with China

\begin{tabular}{|c|c|c|c|}
\hline Year & Exports & Imports & Balance \\
\hline January -July 2009 & $35,662.6$ & $159,130.8$ & -123.468 .2 \\
\hline 2008 & $\mathbf{6 9 , 7 3 2 . 8}$ & $\mathbf{3 3 7 , 7 7 2 . 6}$ & $\mathbf{- 2 5 8 , 0 3 9 . 8}$ \\
\hline 2007 & $\mathbf{6 2 , 9 3 6 . 9}$ & $\mathbf{3 2 1 , 4 4 2 . 9}$ & $\mathbf{- 2 3 4 , 1 0 1 . 3}$ \\
\hline 2006 & $\mathbf{5 3 , 6 7 3 . 0}$ & $\mathbf{2 8 7 , 7 7 4 . 4}$ & $\mathbf{- 2 0 2 , 2 7 8 . 1}$ \\
\hline 2005 & $\mathbf{4 1 , 1 9 2 . 0}$ & $\mathbf{2 4 3 , 4 7 0 . 1}$ & $\mathbf{- 1 6 2 , 2 5 4 . 3}$ \\
\hline 2004 & $\mathbf{3 4 , 4 2 7 . 8}$ & $\mathbf{1 9 6 , 6 8 2 . 0}$ & $\mathbf{- 1 2 4 , 0 6 8 . 2}$ \\
\hline 2003 & $\mathbf{2 8 , 3 6 7 . 9}$ & $\mathbf{1 5 2 , 4 3 6 . 1}$ & $\mathbf{- 1 0 3 , 0 6 4 . 9}$ \\
\hline 2002 & $\mathbf{2 2 , 1 2 7 . 7}$ & $\mathbf{1 2 5 , 1 9 2 . 6}$ & $\mathbf{- 8 3 , 0 9 6 . 1}$ \\
\hline 2001 & $\mathbf{1 9 , 1 8 2 . 3}$ & $\mathbf{1 0 2 , 2 7 8 . 4}$ & $\mathbf{- 1 , 5 5 8 , 8 7 6 . 9}$ \\
\hline TOTAL & $\mathbf{3 6 7 , 3 0 3}$ & $\mathbf{1 , 9 2 6 , 1 7 9 . 9}$ & \\
\hline
\end{tabular}

SOURCE: U.S. Census Bureau, Foreign Trade Division, Data Dissemination Branch, Washington, D.C. 20233 NOTE: All figures are in millions of U.S. dollars, and not seasonally adjusted unless otherwise specified.

Table 3. Nominal GDP sector composition, January 2008

\begin{tabular}{|c|c|c|c|c|c|c|c|c|}
\hline \multicolumn{3}{|c|}{ Number, country, GDP } & \multicolumn{3}{|c|}{$\begin{array}{c}\text { Composition in } \\
\text { percentages }\end{array}$} & \multicolumn{3}{|c|}{ Composition in million dollars } \\
\hline $\mathrm{Nr}$. & Country & GDP & Agri. & Indus. & Serv. & Agri. & Indus. & Serv. \\
\hline 一 & $\underline{\text { World }}$ & $46,660,000$ & $4 \%$ & $32 \%$ & $64 \%$ & $1,866,400$ & $14,931,200$ & $29,862,400$ \\
\hline 一 & European Union & $13,620,000$ & $2.1 \%$ & $27.3 \%$ & $70.5 \%$ & 286,020 & $3,718,260$ & $9,602,1001$ \\
\hline 1 & $\underline{\text { United States }}$ & $13,220,000$ & $0.9 \%$ & $20.4 \%$ & $78.6 \%$ & 118,980 & $2,696,880$ & $10,390,920$ \\
\hline 2 & $\underline{\text { Japan }}$ & $4,911,000$ & $1.6 \%$ & $25.3 \%$ & $73.1 \%$ & 78,576 & $1,242,483$ & $3,589,941$ \\
\hline 3 & Germany & $2,858,000$ & $0.9 \%$ & $29.1 \%$ & $70 \%$ & 25,722 & 831,678 & $2,000,600$ \\
\hline 4 & $\frac{\text { People's Republic of }}{\underline{\text { China }}}$ & $2,512,000$ & $11.9 \%$ & $48.1 \%$ & $40 \%$ & 298,928 & $1,208,272$ & $1,004,800$ \\
\hline 5 & $\underline{\text { United Kingdom }}$ & $2,341,000$ & $1 \%$ & $25.6 \%$ & $73.4 \%$ & 23,410 & 599,296 & $1,718,294$ \\
\hline 6 & $\underline{\text { France }}$ & $2,154,000$ & $2.2 \%$ & $20.6 \%$ & $77.2 \%$ & 47,388 & 443,724 & $1,662,888$ \\
\hline 7 & $\underline{\text { Italy }}$ & $1,780,000$ & $2 \%$ & $29.1 \%$ & $69 \%$ & 35,600 & 517,980 & $1,228,200$ \\
\hline 8 & $\underline{\text { Brazil }}$ & $1,566,253$ & $8 \%$ & $38 \%$ & $54 \%$ & 125,300 & 595,176 & 845,777 \\
\hline 9 & $\underline{\text { Canada }}$ & $1,089,000$ & $2.3 \%$ & $29.2 \%$ & $68.5 \%$ & 25,047 & 317,988 & 745,965 \\
\hline 10 & $\underline{\text { Spain }}$ & $1,081,000$ & $3.9 \%$ & $29.4 \%$ & $66.7 \%$ & 42,159 & 317,814 & 721,027 \\
\hline 11 & $\underline{\text { India }}$ & 796,100 & $19.9 \%$ & $19.3 \%$ & $60.7 \%$ & 158,424 & 153,647 & 483,233 \\
\hline 12 & $\underline{\text { South Korea }}$ & 768,500 & $3.3 \%$ & $40.7 \%$ & $56 \%$ & 25,361 & 312,780 & 430,360 \\
\hline 13 & $\underline{\text { Mexico }}$ & 741,500 & $3.9 \%$ & $25.7 \%$ & $70.5 \%$ & 28,919 & 190,566 & 522,757 \\
\hline 14 & $\underline{\text { Russia }}$ & 733,000 & $5.3 \%$ & $36.6 \%$ & $58.2 \%$ & 38,849 & 268,278 & 426,606 \\
\hline 15 & Australia & 645,300 & $3.8 \%$ & $26.2 \%$ & $70 \%$ & 24,521 & 169,069 & 451,710 \\
\hline
\end{tabular}

SOURCE: U.S. Census Bureau, Foreign Trade Division, Data Dissemination Branch, Washington, D.C. 20233 


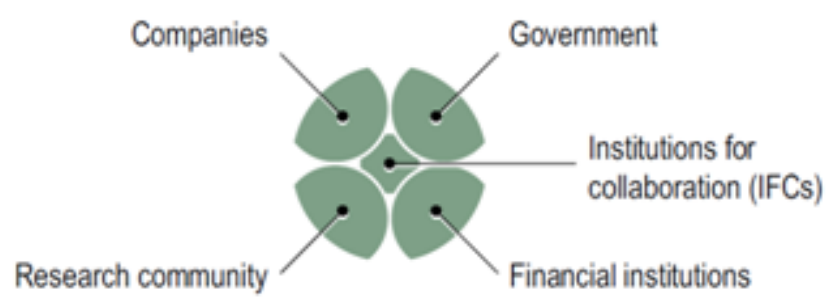

Chart 1. Five sets of actors composing a cluster Source: Center for Strategy and Competitiveness (2003) 